\title{
Assessing the activity of cardiac sympathetic innervation with a novel PET tracer
}

\author{
Ornella Rimoldi
}

Published online: 19 October 2012

(C) Springer-Verlag Berlin Heidelberg 2012

When he was awarded the Nobel Prize in 1970, Ulf von Euler described cardiac adrenergic neurotransmission as follows: "Section of the adrenergic nerves to the heart and some other organs and subsequent degeneration caused the noradrenaline content to fall to very low values, or to disappear, which also indicated that it was normally bound to the nerves in the organs" ... "With the aid of radioactively labelled noradrenaline it could be shown that uptake of transmitter occurred in the particles concomitantly with the release". His seminal work in 1946 was the foundation for the noninvasive study of cardiac sympathetic activity [1].

The sympathetic outflow to the heart is tonically and phasically modulated both in health and disease by the continuous interaction between central neural integration and peripheral inhibitory and excitatory reflexes. The importance of the measurement of neurotransmitter concentrations as an indication of neural activity directed to the heart was highlighted in 1982 by Hasking et al. [2]. The tenet at that time, derived from assays on atrial tissue or papillary muscle samples, was that the failing heart showed a profound depletion of noradrenaline stores. The finding that noradrenaline spillover was increased by $540 \%$ above normal values revealed the overactivity of the sympathetic outflow directed to the heart. A few years later Böhm et al. using tissue samples of the left ventricle proved that there is a presynaptic defect leading to reduced uptake-1 activity in the failing heart. This unpaired mechanism is pharmacologically mimicked by the effects of uptake

\section{O. Rimoldi}

IBFM CNR Milan, Vita-Salute University,

Milan, Italy

O. Rimoldi $(\bowtie)$

Istituto di Bioimmagini e Fisiologia Molecolare, Centro PET,

Settore C, piano-2, Istituto Scientifico Universitario San Raffaele,

Via Olgettina, 60,

20132 Milano, Italy

e-mail: rimoldi.ornella@hsr.it blocking agents in the normal heart [3]. The consequence is an increased synaptic concentration of noradrenaline predisposing to adenylyl cyclase desensitization [3]. Dr. Esler in his recent Paton lecture pointed out that at that time he had "to provide a spirited defence of the research ethics" to carry out invasive noradrenaline spillover measurements in healthy volunteers.

In the last three decades two tracers have been used to assess the function of the reuptake- 1 mechanism noninvasively in humans: ${ }^{123} \mathrm{I}$-metaiodobenzylguanidine $\left({ }^{123} \mathrm{I}\right.$ MIBG) for use with SPECT [4], and ${ }^{11} \mathrm{C}$-hydroxyephedrine $\left({ }^{11} \mathrm{C}-\mathrm{HED}\right)$ [5-7] for use with PET [8]. Both have been used in patients and normal volunteers for a number of years, but so far due to the intrinsic limitations of each radiotracer (Table 1) they have not gained the confidence of practitioners as a guide for the treatment of their patients.

In the early 1990s, a PET tracer labelled with ${ }^{18} \mathrm{~F}\left({ }^{18} \mathrm{~F}-6\right.$ fluorodopamine) was developed [9]. The longer half-life and the theoretical advantage of the physiological characteristics of the tracer, which is internalized into the neuronal terminal vesicles and $\beta$-hydroxylated forming radiolabelled noradrenaline, were negated by the difficult production and modelling, and eventually the tracer failed to enter the clinical arena. The desirable features of the ideal ${ }^{18} \mathrm{~F}$-labelled (PET) radiotracer for imaging the sympathetic efferent innervation are the following: high binding affinity, simple production, high specific activity, long half-life to allow widespread availability, low radiation dose, sound validation in different species including humans.

The paper by $\mathrm{Yu}$ et al. in this issue of EJNMMI [10], describes a cardiac neuronal imaging agent, LMI1195, recently developed by a company manufacturing diagnostic imaging agents [11]. LMI1195 ( $N$-[3-bromo-4-(3-[ $\left[{ }^{18} \mathrm{~F}\right]$ fluoro-propoxy)-benzyl]-guanidine) was designed as a benzylguanidine analogue to act as substrate for the noradrenaline transporter incorporating ${ }^{18} \mathrm{~F}$ to achieve a longer half-life for PET imaging. The authors have demonstrated in a previous 
Table 1 Characteristics of the SPECT tracer ${ }^{123}$ I-MIBG and the PET tracer ${ }^{11} \mathrm{C}$-HED used for the noninvasive assessment of the reuptake-1 mechanism

\begin{tabular}{lll}
\hline & ${ }^{11} \mathrm{C}-\mathrm{HED}$ & ${ }^{123} \mathrm{I}-\mathrm{MIBG}$ \\
\hline Attenuation/scatter correction & Yes & No \\
Affinity & +++ & ++ \\
Half-life & $20 \mathrm{~min}$ & 8 days \\
Acquisition time after injection & $60 \mathrm{~min}$ & 15 min and $4 \mathrm{~h}$ \\
Radiation dose (equivalent dose) $(\mathrm{MBq})$ & $2.11(370$ & 7.03 (370 \\
Availability & Needs on-site cyclotron & Commercially available \\
Image quality & Excellent & Fair \\
Quantification & Full quantification & Semiquantification \\
Active metabolite correction & Yes & No \\
Large clinical cohort studies availability & No & Yes \\
\hline
\end{tabular}

paper the similarity of the kinetics to those of noradrenaline [11], and in this paper they compared the cellular uptake of ${ }^{3} \mathrm{H}$-noradrenaline and ${ }^{123} \mathrm{I}-\mathrm{MIBG}$ in vitro in human neuroblastoma cells expressing noradrenaline. The uptake of LMI1195 was higher than that of ${ }^{3} \mathrm{H}$-noradrenaline and slightly lower than that of ${ }^{123} \mathrm{I}-\mathrm{MIBG}$ with a broader variance, suggesting that LMI195, noradrenaline and MIBG share the same transporter mechanism. The specificity of LMI1195 was shown by a $90 \%$ inhibition of cellular uptake by desimipramine. They moved on to test LMI1195 in vivo in rabbit hearts either intact and innervated or partially denervated with phenol, an experimental model which mimics the damage to neural terminals that has been observed in patients with severe ischaemia [12] or reperfused myocardial infarction [13]. Sympathetic regional denervation had no impact on myocardial perfusion as assessed with flurpiridaz and had reduced the innervated area detected by LMI1195 at 2 weeks after denervation. The number of voxels with tracer uptake increased from 2 to 12 weeks, and the authors suggest that this may indicate nerve sprouting; it is also possible, in my opinion, that this indicates regain of function of neuronal terminals not completely depleted by phenol.

Even though anaesthesia has an impact on autonomic control, controlled experimental conditions offer the advantage of allowing a more accurate evaluation of myocardial uptake and clearance, which can be substantiated by measurement in adequate tissue samples. Unfortunately, validation against tissue content of catecholamines was not performed by Yu et al., although it would have been easy to carry out. A limitation of the paper recognized by the authors themselves is that uptake kinetics under conditions of changing flow in isolated heart preparations were not studied. In my opinion, it is important that a new radiotracer for imaging the uptake-1 mechanism in the heart has to provide the advantages of both ${ }^{123} \mathrm{I}-\mathrm{MIBG}$ and ${ }^{11} \mathrm{C}-\mathrm{HED}$ : it should be easy to obtain and long-lived ( $\left.{ }^{123} \mathrm{I}-\mathrm{MIBG}\right)$ and provide high resolution, image quality and quantification $\left({ }^{11} \mathrm{C}\right.$-HED). If the ambitious goal is to provide a noninvasive tool with additional value for the stratification of patients who are susceptible to life-threatening ventricular tachyarrhythmias and sudden cardiac death, this new tool must overcome the limitations of past approaches. To lend further support to the potential diagnostic use of LMI1195 the authors administered dofetilide, a class III antiarrhythmic agent blocking the delayed rectifier outward potassium current, which induced a greater dose-dependent increase in the $\mathrm{QT}_{\mathrm{cf}}$ interval in the denervated hearts.

Based on these findings $\mathrm{Yu}$ et al. infer that LMI1195 cardiac imaging may potentially provide a means to identify patients with an enhanced risk to the use of dofetilide-like antiarrhythmic agents. It is well demonstrated that heterogeneity of sympathetic innervation and electrical phenomena following myocardial injury are a substrate for lifethreatening arrhythmias [14]. However, the arrhythmic mechanism is more complex in patients with heart failure, coronary disease and ventricular tachycardia/fibrillation in the absence of structural disruption of the myocardial tissue. Sympathetic heterogeneity with areas of denervation, hyperinnervation, and normal nerve density may produce electrical heterogeneity and facilitate the development of ventricular arrhythmias. A low uptake of the tracer in a definite region can have a binary interpretation: on the one hand it might indicate a lower density of neural terminals which have been damaged, and on the other hand sympathetic overactivity may increase the amount of endogenous mediator in the synaptic cleft which displaces the radiotracer. The latter phenomenon has been quantified using ${ }^{11} \mathrm{C}$-HED and is distinctive of arrhythmogenic cardiomyopathies [6, 7].

It is possible that neuronal imaging with LMI195 may play a role as a risk predictor in efficiently identifying those patients who will surely benefit from implantable devices. But, in order to achieve this goal, more controlled preclinical and clinical studies are warranted to assess the extent to which what has been measured in rodents is applicable to human pathophysiology. Finally, the establishment of an extensive database of normal values for both genders and over a wide age span is the key to an expanded clinical application of PET imaging with LMI1195 to monitor the subtle changes of cardiac sympathetic modulation. 


\section{References}

1. Euler UV. Adrenergic neurotransmitter functions. 12 December 1970. Stockholm: Nobel Lecture. http://www.nobelprize.org/nobel_prizes/ medicine/laureates/1970/euler-lecture.pdf. Accessed 3 Oct 2012.

2. Hasking GJ, Esler MD, Jennings GL, Burton D, Johns JA, Korner PI. Norepinephrine spillover to plasma in patients with congestive heart failure: evidence of increased overall and cardiorenal sympathetic nervous activity. Circulation. 1986;73:615-21. doi:10.1161/ 01.cir.73.4.615.

3. Böhm M, La Rosée K, Schwinger RHG, Erdmann E. Evidence for reduction of norepinephrine uptake sites in the failing human heart. J Am Coll Cardiol. 1995;25:146-53.

4. Jacobson AF, Senior R, Cerqueira MD, Wong ND, Thomas GS, Lopez VA, et al. Myocardial iodine-123 meta-iodobenzylguanidine imaging and cardiac events in heart failure. Results of the prospective ADMIRE-HF (AdreView Myocardial Imaging for Risk Evaluation in Heart Failure) study. J Am Coll Cardiol. 2010;55:2212-21.

5. John AS, Mongillo M, Depre C, Khan MT, Rimoldi OE, Pepper JR, et al. Pre- and post-synaptic sympathetic function in human hibernating myocardium. Eur J Nucl Med Mol Imaging. 2007;34:1973-80.

6. Kies P, Wichter T, Schafers M, Paul M, Schafers KP, Eckardt L, et al. Abnormal myocardial presynaptic norepinephrine recycling in patients with Brugada syndrome. Circulation. 2004;110:3017-22. doi:10.1161/01.CIR.0000146920.35020.44.

7. Schafers M, Dutka D, Rhodes CG, Lammertsma AA, Hermansen F, Schober O, et al. Myocardial presynaptic and postsynaptic autonomic dysfunction in hypertrophic cardiomyopathy. Circ Res. 1998;82:57-62.

8. Carrio I. Cardiac neurotransmission imaging. J Nucl Med. 2001;42:1062-76.

9. Goldstein DS, Eisenhofer G, Dunn BB, Armando I, Lenders J, Grossman E, et al. Positron emission tomographic imaging of cardiac sympathetic innervation using 6-[18F]fluorodopamine: initial findings in humans. J Am Coll Cardiol. 1993;22:1961-71.

10. Yu M, Bozek J, Lamoy M, Kagan M, Benites P, Onthank D, et al. LMI1195 PET imaging in evaluation of regional cardiac sympathetic denervation and its potential role in antiarrhythmic drug treatment. Eur J Nucl Med Mol Imaging. 2012. doi:10.1007/ s00259-012-2204-y.

11. Yu M, Bozek J, Lamoy M, Guaraldi M, Silva P, Kagan M, et al. Evaluation of LMI1195, a novel 18F-labeled cardiac neuronal PET imaging agent, in cells and animal models. Circ Cardiovasc Imaging. 2011;4:435-43.

12. Bulow HP, Stahl F, Lauer B, Nekolla SG, Schuler G, Schwaiger M, et al. Alterations of myocardial presynaptic sympathetic innervation in patients with multi-vessel coronary artery disease but without history of myocardial infarction. Nucl Med Commun. 2003;24:233-9.

13. Calkins H, Allman K, Bolling S, Kirsch M, Wieland D, Morady F, et al. Correlation between scintigraphic evidence of regional sympathetic neuronal dysfunction and ventricular refractoriness in the human heart. Circulation. 1993;88:172-9.

14. Goldberger JJ, Buxton AE, Cain M, Costantini O, Exner DV, Knight BP, et al. Risk stratification for arrhythmic sudden cardiac death. Circulation. 2011;123:2423-30. 